\title{
Concílio Vaticano II: novo horizonte para o diálogo da Igreja com o
} mundo moderno

\section{Maria Carmen Castanheira Avelar ${ }^{1}$}

\section{Esclarecimentos iniciais}

Os jovens são os interlocutores principais deste texto. Junto com eles, acredito que estejam os adultos educadores, evangelizadores e todos aqueles e aquelas que circulam no âmbito das diferentes juventudes. Por que os jovens? Por ser este um dos objetivos da revista CRE-ATIVIDADE. É a partir dos jovens, das juventudes de hoje, que vou delineando estas palavras, que vou escolhendo o conteúdo e o estilo do texto.

Os jovens de hoje, na sua grande maioria, não conhecem o Concílio Vaticano II. Jovens que não frequentam a Igreja, jovens das diferentes religiões, ateus, agnósticos, indiferentes às religiões ... $\mathrm{e}$ jovens que frequentam a Igreja também podem ser incluídos neste universo de pessoas. Incluo aqui também os jovens que frequentam universidades ou escolas católicas ou que provêm de outros segmentos religiosos cristãos. Pessimismo? Há mais de 30 anos trabalhando com jovens e adolescentes, creio poder arriscar nesta afirmação. Por isto, é preciso anunciar-Ihes pelo menos alguns traços deste importante evento - Concilio Vaticano II (1962-1965) - que muito contribuiu para a abertura da Igreja à sociedade moderna e para o diálogo dos católicos com as diferentes juventudes. O Concílio Ecumênico Vaticano II foi convocado pelo Papa João XXIII em 25 de dezembro de 1961. A abertura oficial deste Concílio aconteceu com a liderança do mesmo Papa João XXIII em 11 de outubro de 1962 e foi encerrado pelo Papa Paulo VI em 8 de dezembro de 1965 (Compêndio do Vaticano II, 1968).

Logo, é preciso esclarecer alguns conceitos:

\section{O Concilio Vaticano II é um Concílio Ecumênico da Igreja Católica.}

\subsection{O que é um concílio?}

\footnotetext{
${ }^{1}$ Profa. da Cultura Religiosa da PUC-Rio. Doutora em Teologia (PUC-Rio), Mestra em Psicologia da Educação (FGV), Especialista em Espiritualidade Juvenil (UP.S - ROMA).
} 
Concílio é a assembleia de todos ou de quase todos os Bispos do mundo inteiro que, em comunhão com o Papa, Bispo de Roma e Sucessor de Pedro, procuram esclarecer questões da fé cristã, da moral ou do dinamismo pastoral e missionário da Igreja. Os concílios são momentos fortes e importantíssimos para a vida de toda a comunidade dos discípulos de Cristo, para a Igreja católica. O concilio pode contar também com a possível participação de outras pessoas - outros membros da hierarquia, leigos e também membros observadores de outras Igrejas cristãs.

\subsection{E por que ecumênico?}

Ecumênico aqui não significa que seja uma reunião com outras religiões. O termo "ecumênico" quer significar que as decisões tomadas no Concílio dizem respeito às igrejas cristãs católicas espalhadas por todo o mundo. Ele tem autoridade sobre toda a Igreja Católica, pois aí está reunido o Colégio dos Bispos juntamente com o Papa. Neste sentido, diferencia-se dos concílios regionais ou nacionais, com Bispos só de uma região ou de um país. (At 15,28). De fato, esta grande assembleia é uma grande reunião, envolvendo bispos de todo o mundo sob a liderança do Papa, contando com a assessoria de peritos, de especialistas em diferentes áreas da Teologia cristã católica ou de outras áreas do conhecimento. Para que? Para tomarem decisões importantes para o dinamismo religioso/pastoral, para a vivência religiosa/eclesial de todos os católicos, na atualidade. Em base a esta afirmação, um Concílio Ecumênico da Igreja Católica, requer um significativo aparato. Se houvesse um concílio ecumênico, no século XXI, os Bispos convocados chegariam a mais de 5000. E, com eles, o Papa, cardeais, peritos de diferentes áreas, e outros convidados observadores.

Concílio Ecumênico, como dissemos anteriormente, indica que esta assembleia se refere às comunidades católicas do mundo inteiro, portanto é Universal. Contudo, no Concílio Ecumênico Vaticano II, o termo ecumênico também foi utilizado para explicitar o objetivo de abertura aos cristãos de outras denominações cristãs. O termo, desde então, indica o movimento de busca da unidade entre cristãos de diferentes Igrejas, espalhadas pelo mundo todo. $O 1^{\circ}$ Concílio Ecumênico aconteceu em Jerusalém, nos anos 48 e 49 d.C. (Atos 15). O grande tema foi a questão levantada por "alguns do partido dos fariseus que haviam 
abraçado a fé cristã, declarando que era preciso circuncidar os gentios e impor-Ihes a observância da Lei de Moisés" (At 15,5). O debate foi muito longo e intenso. Contou com a participação de Paulo e Barnabé missionários entre os "pagãos", e também de Tiago, junto com Pedro, e outros provenientes de Antioquia. Paulo defendeu a não imposição dos ritos judaicos aos novos cristãos (como a prática da circuncisão judaica). Depois dos discursos de Tiago, de Pedro e de argumentos de Paulo, a assembleia decidiu que não se deviam impor jugos provenientes da tradição judaica aos novos cristãos gregos, de Antioquia e aos outros de origem helenística (At 15,24ss). Felizmente, venceu a perspectiva de abertura aos novos cristãos, indicando o acolhimento respeitoso de outros povos no seguimento, no projeto de Jesus, não lhes impondo o cumprimento da Lei de Moisés (At 15,1-35). Hoje, podemos dizer que, nas origens da divulgação do Cristianismo, o anúncio da Fé Cristã praticou, de certa forma, o ecumenismo que apregoa a Unidade na Pluralidade. Um Concílio Ecumênico precisa ser movido pelo combustível da abertura agregadora do espírito evangélico. E foi neste clima que se desenrolaram os trabalhos do Concílio Vaticano II, ainda que tenha havido discussões acaloradas e posicionamentos divergentes entre os participantes.

\subsection{Os 21 concílios da Igreja}

Ao longo da história, já foram convocados 21 concílios ecumênicos, além do $1^{\circ}$ Concílio de Jerusalém, citado acima. Note-se que os concílios recebem o nome do local onde são realizados. É curioso o fato de que apenas 2 foram realizados no Vaticano. A seguir, os 21 concílios da Igreja Católica, a saber: Concílio de Nicéia, em 325; Concílio de Constantinopla, em 381; Concílio de Éfeso, em 431; Concílio de Calcedônia, em 451; Concílio de Constantinopla II, em 553; Concílio de Constantinopla III, em 680-681; Concílio de Nicéia II, em 787; Concílio de Constantinopla IV, em 869-870; Concílio de Latrão I, em 1123; Concílio de Latrão II, em 1139; Concílio de Latrão III, em 1179; Concílio de Latrão IV, em 1215; Concílio de Lião I, em 1245; Concílio de Lião II, em 1274; Concílio de Viena-França, em 1311-1312; Concílio de Constança, em 1417; Concílio de Ferrata-Florença, em 1438-1445; Concílio de Latrão V, em 1512-1517; Concílio de Trento, em 1545-1547//1551-1552//1562- 
1563; Concílio Vaticano I, em 1869-1870; e Concílio Vaticano II, em 19621965.

Chama atenção a longa duração do Concilio de Trento (1545 a 1563), realizado no difícil momento eclesial, em que despontaram as questões levantadas por Martinho Lutero, Calvino e outros reformadores. Neste texto, não é possível dedicar tempo à consideração das temáticas e dos objetivos de cada Concílio. Todos eles foram motivados pela necessidade de tomar decisões, esclarecimentos de caráter doutrinal pastoral que garantissem unidade entre os católicos e o dinamismo pastoral/eclesial.

\subsection{Sínodo}

Hoje em dia ouve-se falar mais em sínodo do que em concilio. Por isto, vamos fazer mostrar a diferença entre ambos. No ano passado, aconteceu o Sínodo dos Bispos para os Jovens de 03 a 28 de outubro de 2018 no Vaticano. Este ano, será realizado o Sínodo para a Amazônia. O Sínodo para Amazônia foi uma resposta do Papa Francisco à realidade da Pan-Amazônia. Será realizado em outubro de 2019 com o tema "Amazônia: novos caminhos para a Igreja e para uma Ecologia Integral". O sínodo implica em uma organização menos complexa do que o concílio", pois dele participam somente alguns bispos representando o Colegiado Episcopal do mundo todo, enquanto que para o concílio assembleia mais ampla - todos os Bispos são convocados.

Resgatando o sentido etimológico da palavra "sínodo", chega-se aos termos gregos syn (que significa "juntos") e hodos (que significa "caminho"), numa junção que expressa a ideia de "caminhar juntos". O sínodo da Igreja consiste em um encontro religioso ou assembleia na qual alguns bispos, reunidos com o papa, têm a oportunidade de trocarem informações e compartilhar experiências e que tem como tarefa ajudar o Papa no governo da Igreja universal dando-Ihe seu conselho (vatican.va).

\section{Convocação do Concílio Vaticano II}

No dia 28 de outubro de 1958, Angelo Roncalli foi eleito Papa em substituição a Pio XII (1939-1958), escolhendo o nome de João XXIII. Pio XII, verdadeiro diplomata e de reconhecida cultura e capacidade intelectual, foi, então, substituído por João XXIII, filho de camponeses, 
nascido no vilarejo de Soto il Monte (Itália), eleito aos 78 anos de idade. Muitos acreditavam que seu pontificado seria apenas um período de transição, sem feitos expressivos e que pouca coisa mudaria à espera de outro Papa mais jovem que pudesse empreender a tão esperada reforma e ABERTURA da Igreja ao mundo moderno. De fato, muitos observadores julgavam que, aos 78 anos, o Papa João XXIII realizaria pouco à frente da Igreja (BEOZZO, 2005). Todavia, no dia 25 de janeiro de 1959, quando João XXIII ainda não havia completado 100 dias de pontificado, o mundo foi pego de surpresa com o anúncio da convocação de um concílio ecumênico, o que não acontecia há quase um século na Igreja. O último concílio ecumênico - concilio Ecumênico Vaticano I havia sido interrompido pelo Papa Pio IX, em 1871, por causa das sérias questões políticas italianas. O debate sobre importantes questões doutrinárias, pastorais, eclesiais permaneceu, em parte, inconclusas no difícil momento da história da Igreja em que faltava abertura, diálogo com o mundo moderno que exigia sérias respostas da Igreja.

Ao anunciar a realização do Concilio Ecumênico Vaticano II, o Bondoso Papa João XXIII chamou a atenção da opinião pública mundial e capturou a sua imaginação:

"provocou por todo o mundo excitação e grandes indagações. Deixou perplexos os cardeais presentes, mas levantou na opinião pública mundial, católica e leiga, imediata onda de esperança e otimismo pelo seu anunciado propósito de buscar, num mundo dilacerado por divisões políticas e religiosas, a unidade dos cristãos e, num horizonte mais amplo, a unidade de toda a família humana" (Beozzo, 2005).

O objetivo ecumênico do Concílio Vaticano II visava a abertura de diálogo com a sociedade do século XX, de acolhimento do homem, da mulher, dos jovens dos tempos modernos e também de abertura e de acolhida de outros segmentos religiosos cristãos e não cristãos. Este importante objetivo veio junto com a meta de anunciar a doutrina, a fé cristã de modo eficaz e atualizado. A preocupação da Igreja era o mundo moderno e modo de dialogar com ele.

A intenção da convocação era mais com uma preocupação pastoral do que doutrinária/dogmática. Em seu discurso inaugural, o Papa João XXIII posicionou o objetivo geral deste evento: 
a finalidade principal deste Concílio não é, portanto, a discussão de um ou outro tema da doutrina fundamental da Igreja, repetindo e proclamando o ensino dos Padres e dos Teólogos antigos e modernos, que se supõe sempre bem presente e familiar ao nosso espírito. Para isto, não havia necessidade de um Concílio. Mas da renovada, serena e tranquila adesão a todo o ensino da Igreja, na sua integridade e exatidão, ... o espírito cristão, católico e apostólico do mundo inteiro espera um progresso na penetração doutrinal e na formação das consciências; é necessário que esta doutrina certa e imutável, que deve ser fielmente respeitada, seja aprofundada e exposta de forma a responder às exigências do nosso tempo. Uma coisa é a substância do depositum fidei, isto é, as verdades contidas na nossa doutrina, e outra é a formulação com que são enunciadas, conservando-lhes, contudo, o mesmo sentido e o mesmo alcance. (Discurso Inaugural do Papa João XXIII - 1962)

Neste discurso, o Papa João XXIII insistiu na importância da forma de apresentação da fé cristã, do corpo doutrinário cristão ao mundo moderno, à sociedade do século XX e nós diríamos, agora, do século $X X I$. Com este objetivo, foi instituída uma comissão preparatória do Concílio Vaticano II. Esta comissão escreveu cartas aos bispos do mundo inteiro para que eles ajudassem, indicando as problemáticas de cada Igreja particular. Isto é, das diferentes comunidades cristãs católicas, situadas em todo o mundo. No dia 05 de junho de 1960, a fase preparatória começou com o objetivo de elaborar esquemas que pudessem dirigir as reflexões durante o concílio. A partir desta sondagem, no dia 11 de outubro de 1962, na solene abertura do vigésimo primeiro Concílio Ecumênico Vaticano II, na festa de Pentecostes do ano do anúncio, do qual participaram cerca de 2.400 bispos, foi organizada uma comissão para elencar os pontos importantes a serem tratados. A partir deste levantamento, foram organizados os temas a serem discutidos durante o longo período de realização do Concilio Vaticano II (Beozzo, 2005).

Os trabalhos se desenvolveram em 4 sessões:

I - de $11 / 10$ a 08/12 de 1962

II - de 29/09 a 04/12 de 1963

III - de 14/09 a 21/11 de 1964

IV - de 14/09 a 08/12 de 1965 
Pode-se imaginar as proporções da logística que garantiu o bom funcionamento dos trabalhos e as despesas daí decorrentes. Além dos 2.4000 bispos, participaram, como observadores, membros de outras Igrejas - cristãs e de outras religiões -, religiosos e religiosas além de leigos.

Em termos de conteúdo, depois de muitos debates, divergências e discussões o concílio produziu ao todo 16 documentos, não com o objetivo de modificar a doutrina e sim com a finalidade de orientar como comunicar os conteúdos da fé cristã, através de uma formulação, de uma comunicação, que atinja o homem/mulher de hoje. Uma atitude dialogante, de abertura, de acolhida dos anseios do mundo moderno. Esta meta orientou os Padres Conciliares, na longa rotina de discussões, emendas e votações dos temas propostos até alcançar a unidade na correspondência com a fé para se promulgar um texto. E este trabalho não foi fácil: chegar a esta unidade, em uma assembleia constituída por mais de 2.000 participantes implicou em muitas discussões, em apresentação de ideias divergentes (cf. Compêndio do Vaticano II (1968).

\section{Os documentos conciliares}

Este trabalho gerou ao todo 16 documentos (4 constituições, 3 declarações e 9 decretos).

- As Constituições expõem as verdades de fé e os elementos essenciais da Igreja. As 4 Constituições tiveram um destaque especial: sobre a Liturgia (Sacrosanctum Concilium) sobre a natureza e a organização/missão da Igreja no mundo moderno (Lumen Gentium); sobre a Revelação e a transmissão da Palavra (Dei Verbum); e sobre a relação da Igreja com o mundo moderno (Gaudium et Spes).

- As Declarações expõem a visão da Igreja sobre determinadas questões importantes da sociedade: educação católica; relação entre a lgreja e os não-cristãos; liberdade religiosa, sempre com a preocupação de abertura e diálogo em linguagem compreensível com o mundo moderno:

- Os Decretos apresentam as normas disciplinares e pastorais advindas da reflexão conciliar. Os temas enfocados foram: o Ecumenismo, as 
igrejas orientais católicas; a formação dos presbíteros; a vida religiosa consagrada; o serviço pastoral dos bispos; o apostolado dos leigos; a atividade missionária da Igreja; o ministério e a vida do presbítero; a relação da Igreja com os meios de comunicação social (Cf. Compêndio do Vaticano II, 1968)

Apresentadas as temáticas, podemos verificar o grande alcance das questões aí envolvidas e que dizem respeito à dinâmica, à organização eclesial, isto é da Igreja, e à sua relação com o mundo de hoje.

\section{Preocupações que orientaram os trabalhos conciliares}

O Concílio Ecumênico Vaticano II não se propôs a ser uma repetição dos 20 Concílios Ecumênicos anteriores. "Ele queria, para os dias de hoje, uma releitura da doutrina já definida no passado. Teria que se preocupar fundamentalmente com o caminho necessário para o mundo de hoje, abrir-se ao Evangelho: como evangelizar o mundo de hoje? Como anunciar o Evangelho para o mundo de hoje e como vivê-lo neste nosso mundo: (D. A. Lorscheider, 2005). Segundo Dom Lorscheider, duas são as palavras que sintetizam as preocupações do Concílio Vaticano II:

a- AGGIORNAMENTO - com os seus quase sinônimos: atualização, renovação, rejuvenescimento - da Igreja, com mais acentuada atitude de diaconia e serviço;

b- DIÁLOGO DA IGREJA - consigo mesma, com as outras Igrejas e outras religiões, com o mundo dos não-crentes. Neste contexto, aparecem como sinônimos do diálogo: comunhão, participação, coresponsabilidade. (cf. Lorschider, p. 39-40).

Podemos conferir também o texto do Padre Comblin, desdobrando as 2 palavras-chave em 7 palavras decorrentes das 2 citadas anteriormente e que nortearam os debates e a elaboração dos documentos conciliares. A saber:

1.O SER HUMANO (HOMEM/MULHER) - uma vez que a preocupação pela humanidade, pelo ser humano está subjacente em todos os documentos do Concílio, porque "sempre houve o interesse de 
apresentar as realidades da Igreja como resposta às necessidades ou às aspirações do homem moderno" (Comblin, 2005);

2.LIBERDADE - foi graças ao reconhecimento da liberdade do ser humano para escolher sua opção religiosa, que se tornou possível dar ênfase ao ecumenismo e ao diálogo inter-religioso. No concílio, a palavra liberdade passou a ser usada sem restrições e recebeu um sentido positivo (Comblin, 2005);

3.POVO DE DEUS: comunhão e participação. Na Lumen Gentium, importante constituição do Concílio Vaticano II, no capítulo II, o tema do Povo de Deus ocupa lugar central. Até precede o capítulo sobre a Hierarquia da Igreja (Cap. III). O Concílio recuperou a importância da Igreja, entendida com a categoria de Povo de Deus. A missão da Igreja é reunir filhos e filhas de Deus, num só Povo, incluindo a todos na missão de anunciar o Evangelho, de assumir a vocação missionária e o chamado à santidade.

4- COLÉGIO EPISCOPAL - COLEGIALIDADE. Não aparece nos textos conciliares, mas, desde então "foi usada frequentemente para comentar os textos e expressa uma das grandes aspirações da assembleia conciliar e da Igreja inteira" (Comblin, 2005): conseguir uma forma de governo eclesial mais participativa.

5-DIÁLOGO - Embora o Papa João XXIII tenha usado o termo MISERICORDIA para orientar a relação da Igreja com os tempos modernos, evitando condenações e severidade, o Papa Paulo VI sucessor de João XXIII - apoiou a utilização da palavra diálogo "que deve substituir as relações de dominação e de superioridade, utilizadas em outras épocas. O diálogo deve ser uma expressão da caridade, por levar em conta outras pessoas, que são diferentes, e não julgá-las com base em princípios abstratos supostamente universais" (Comblin, 2005).

6.SERVIÇO - Na Igreja, concebida como hierarquia, predominava o conceito de poder. Essa teologia do poder perdeu sentido no contexto de retorno à Bíblia. No Novo Testamento prevalece o linguajar do Serviço. O próprio Jesus se fez servidor e indicou aos discípulos este caminho: "O maior entre vós seja o menor, seja servidor", (cf Mt 20, 24-28): . ... aquele que quiser tornar-se grande entre vós seja aquele que serve, e quem 
quiser ser o primeiro dentre vós, seja o vosso servo...). "De acordo com o Vaticano II, a Igreja existe para servir não para ser servida. Ela não reclama para si nenhuma autoridade senão a de servir os homens. Os ministros da lgreja devem servir seus irmãos. A missão dos Bispos é o serviço" (Comblin, 205), contrariando, assim, a forte tendência existente no clericalismo de busca do poder.

7- MISSÃO - O termo missão, atividade missionária, era, antes do Vaticano II, utilizado para designar o trabalho evangelizador de alguns enviados da Igreja a terras distantes de pessoas não cristãs. Com o Concílio Vaticano II, missão refere-se ao trabalho evangelizador de toda a Igreja, de todos os cristãos e cristãs "E este programa de evangelização do mundo tornou-se a prioridade da Igreja toda - pelo menos na teoria" (Comblin, 2005). Uma Igreja em missão, uma Igreja em saída, que sai da sacristia e se coloca junto do povo (cf. Papa Francisco, 2017).

\section{Palavras finais}

Reconheço que, nestas poucas páginas, não posso abordar, comunicar, comentar toda a relevância do Concílio Vaticano II. Espero que os leitores/as tenham sido despertados para o aprofundamento do tema e que se interessem por leituras relativas ao mesmo. Aqui, preciso dizer que, atualmente, percebe-se um certo esfriamento em relação ao Concílio Ecumênico Vaticano II. Como anunciamos, no inicio do texto, esta grande Assembleia, convocada pelo iluminado e santo Papa João XXIII - o Papa Bom -, como era chamado, despertou de fato, em todo o mundo católico, um forte sentimento de otimismo, de esperança: a Igreja, que parecia envelhecer, precisava tirar as rugas do rosto, fazer-se significativa e cheia de vigor para melhor servir o povo de Deus, os diferentes povos mais necessitados e dialogar com a sociedade moderna, pós-moderna, com abertura, acolhimento e misericórdia. Os longos trabalhos desenvolvidos no período de quase 4 anos foram acompanhados por católicos, por cristãos e pela sociedade, com expectativa e interesse. Nem o falecimento do querido Papa João diminuiu a esperança de uma consistente renovação da Igreja Católica. Aliás, o sucessor do santo Papa João XXIII, o santo Papa Paulo VI, também orientou o Concílio, com muita sabedoria, nas etapas finais dos trabalhos e nos períodos pós-capitulares, na implantação, vamos assim dizer, das orientações e conclusões conciliares. 
Houve, sim, um período de receptividade, de adesão, de esforço para estudar os documentos e para agilizar mudanças. Basta que nos lembremos de que houve acentuadas modificações nas celebrações eucarísticas. O latim foi substituído pelas línguas vernáculas. Ritmos musicais mais populares foram introduzidos, junto com a permissão do uso de violões, guitarras e outros instrumentos musicais, tirando, assim, a exclusividade de órgãos, harmônios e das melodias mais tradicionais e universais. As Igrejas locais, conferências episcopais, representativas das diferentes regiões passaram a ter mais atuação e autonomia. A participação dos leigos passou a ser mais valorizada e requisitada. O diálogo ecumênico tomou um grande impulso. A vida consagrada religiosa sofreu mudanças no sentido de seus membros - religiosos $e$ religiosas - saírem dos conventos e se colocarem junto do povo. É reconhecido o empenho do Papa Paulo VI no aprofundamento da missão da Igreja: Igreja, o que dizes de ti mesma? Como a Igreja é chamada a dialogar com o mundo de hoje, com os jovens, com os sofredores? (Paulo VI, discurso de 29/09 -1963 e a Encíclica Ecclesiam Suam - 06/08 -1964).

Mais de 50 anos depois do término do Concílio Vaticano II, podemos nos perguntar: a Igreja alcançou os objetivos propostos por este importante acontecimento? O Concílio Vaticano II, com seus propósitos de abertura e renovação, de diálogo com a sociedade, continua inspirando a dinâmica da vida eclesial e das atividades pastorais? Estas e outras perguntas vêm preocupando alguns a dizer como se sentem incluídos, valorizados, compreendidos, nesta dinâmica eclesial.

Reporto-me à visão otimista do saudoso e grande teólogo João Batista Libânio: "O Concílio Vaticano II (1962-1965) foi um evento histórico datado. ... Pertence à história... encerrado na sua realização como acontecimento pontual, começa um novo movimento de sua história que propriamente não terá fim, com maior ou menor influência sobre a realidade que se Ihe seguirá." (LIBÂNIO, 2005). Podemos dizer que ainda é tempo da recepção, de consideração, de estudo, de fazer acontecer o Concilio.

Citamos também as observações de outro teólogo, José Maria Vigil (2005) que reconhece a grandeza histórica do Vaticano II, mas que faz outros questionamentos. À luz dos questionamentos de Vigil, podemos dizer que o Concilio Ecumênico Vaticano II precisa continuar a 
ser lido em sua perspectiva de abertura, de diálogo, de sensibilidade diante dos problemas, das contínuas mudanças do mundo da atualidade (VIGIL, 2005): "As alegrias e as esperanças, as tristezas e as angústias dos homens de hoje, sobretudo dos pobres e de todos os que sofrem, são também as alegrias e as esperanças, as tristezas e as angústias dos discípulos de Cristo ...Para desempenhar tal missão, a Igreja, a todo momento, tem o dever de perscrutar os sinais dos tempos e interpretálos à luz do Evangelho, de tal modo que possa responder, de maneira adequada a cada geração, presente e futura e de suas relações mútuas" (Constituição Gaudium et Spes, sobre o Homem no Mundo de Hoje, Vaticano II 1965)

Concluo, reafirmando que o Concílio Vaticano II foi o maior evento histórico da Igreja Católica dos últimos tempos. Este evento não está encerrado, pois sua força simbólica continua impulsionando a dinâmica pastoral e eclesial da Igreja Católica. Infelizmente, existem aqueles e aquelas que confundem a fé com suas expressões culturais. O Vaticano Il deixou-nos o forte legado do diálogo com a sociedade atual, indicou o caminho da inserção no mundo moderno, valorizou as diferentes culturas, as expressões culturais da fé. Não podemos confundir fundamentalismo doutrinário com fidelidade à fé. A fé cristã é a mesma, sempre. Contudo, as expressões dos conteúdos da fé cristã - os mesmos, ontem, hoje e sempre, - devem ser inculturadas, devem ser anunciadas a partir de dentro das culturas nas quais a fé cristã é anunciada. Paulo, em suas cartas, apresenta-nos fortes exemplos de evangelização, de anúncio da fé cristã, de forma inculturada, respeitosa em relação às diferentes comunidades de cultura grega, helenística. Creio que a confusão existente ainda hoje entre a fidelidade à fé cristã e sua expressão, sua forma de comunicação, de sua explicitação, criou muitos obstáculos para o processo de atualização, de renovação proposto pelo Vaticano II.

Reafirmamos: continua inesquecível o impulso lançado pelo Concílio Vaticano II sobre a importância do "aggiornamento" - renovação - e sobre o diálogo, sobre a Igreja que se coloca, em atitude de serviço. Este impulso continua vivo, orientando a dinâmica, a organização da Igreja e os trabalhos pastorais e de evangelização missionária. Este processo de abertura e de diálogo deve continuar, pois a Igreja Católica quer se colocar sempre em atitude de escuta, de diálogo, de serviço, de 
anúncio do projeto de Jesus a todos os homens e mulheres, do mundo todo.

\section{BIBLIOGRAFIA}

- Bíblia de Jerusalém

- Compêndio do Vaticano II - Constituições, decretos, Declarações, Editora Vozes: Petrópolis, 2005;

- PAPA JOÃO XXIII, Discurso de Abertura do Concílio Vaticano II, Observatore Romano: Vaticano, 1962;

- FRÖHLICH, Roland, Curso Básico de História da Igreja, Paulus: São Paulo, 1987;

- LENZENWEGER,J. e outros, Historia de la Iglesia Católica, Herder: Barcelona, 1989;

- LORSCHEIDER, Aloísio e outros, VATICANO II: 40 anos depois, Paulus: S. Paulo, 2005;

-www.vatican.va, Concílio Vaticano II

-Wiki Canção Nova, Concílio Vaticano II 